\title{
Research Advance in the Efficacy and Mechanism of Qing Fei Xiao Yan Wan for the Treatment of Respiratory Diseases
}

\author{
Junying Ding1, Qingquan Liu ${ }^{1,2 *}$ \\ ${ }^{1}$ Beijing Research Institute of Traditional Chinese Medicine (TCM), Beijing, China \\ ${ }^{2}$ Beijing Hospital of Traditional Chinese Medicine (TCM), Capital Medical University, Beijing, China \\ Email: *iyd0311@126.com
}

Received 6 June 2014; revised 4 July 2014; accepted 1 August 2014

Copyright (C) 2014 by authors and Scientific Research Publishing Inc.

This work is licensed under the Creative Commons Attribution International License (CC BY).

http://creativecommons.org/licenses/by/4.0/

c) (i) Open Access

\begin{abstract}
Qing Fei Xiao Yan Wan had been incorporated into the existing "Chinese Pharmacopoeia", protected by patents. The manufacturing process of it was scientific and its compatibility was reasonable. It was also shown by clinical trials that the efficacy is exact. Clinical trials and experiment studies had confirmed the efficacy and some mechanism for the treatment of respiratory diseases, which were summaried in this paper. Combined with the experimental results (published in another paper), the other prospect application was further discussed.
\end{abstract}

Keywords

Qing Fei Xiao Yan Wan, Clinical Trials, Experiment Studies, Mechanism, Efficacy

\section{Introduction}

Qing Fei Xiao Yan Wan (QFXYW) has been included into the current Pharmacopoeia of China and in the patent protection for 20 years.

On the basis of “Ma Xing Shi Gan Tang” from “Treatise on Febrile Diseases” [1] [2], QFXYW is composed by Ephedra sinica, Cypsum fibrosum, Armeniacae seme (parch), Angle worm, Great burdock achene, Tansymustard seed, Bezoar and Cornu antelopis [3]. It is made by modern honey pill production technology with low temperature vaccum drying process. Especially when the vacuum drying technology is at $4^{\circ} \mathrm{C}$, the evaporation and thermal components can be preserved to the maximum extent [4]. While traditional high-temperature drying technology affects seriously heat-sensitive components, for example, Calculus bovis is easily volatile degenera-

${ }^{*}$ Corresponding author.

How to cite this paper: Ding, J.Y. and Liu, Q.Q. (2014) Research Advance in the Efficacy and Mechanism of Qing Fei Xiao Yan Wan for the Treatment of Respiratory Diseases. Modern Research in Inflammation, 3, 113-121.

http://dx.doi.org/10.4236/mri.2014.33014 
tion [5].

\section{Efficacy}

\subsection{Efficacy of Ingredients}

Ephedra sinica and Gypsum fibrosum were conducive to eliminating pathogen because one could help dispersion and the other could help depuratory. Meanwhile one is hot and the other is cold, which is fit for opening the inhibited lung-energy [6]-[9]. Ephedra sinica and Armeniacae seme (parch) could facilitate the flow of gastric gas to relieve asthma [10]. Ephedrin of Ephedra sinica could excite $\beta$-adrenergic receptors to relieve bronchial smooth muscle spasm [11] [12]. Great burdock achene (Fructus Arctii) and Tansymustard seed had significantly antiviral and antibacterial [13] [14] effects. Tansymustard seed could dissipate phlegm, remove heat from lung and relieve asthma, which played an Pulmonary edema relief role [14]. Angle worm (Dilong) and Bezoar had a very strong anti-inflammatory effect [15] [16], especially the anti-inflammatory effect of Bezoar was 33 times than that of hydrocortisone. Bezoar also had the effect of activating blood circulation, removing blood stasis, and preventing blood hypercoagulation [17]. Angle worm could eliminate phlegm and inhibite tracheal smooth muscle spasm. Cypsum fibrosum, Bezoar and Great burdock achene had heat-clearing and detoxicating effects. Cornu antelopis had unique effects of pyretolysis, regulating immunity, antibacterial and anti-viral infection [18]. Cornu antelopis had an efficient effect on flu and recurrent respiratory infections in children, and was difficult to generate antibiotic-like drug-resistance.

\subsection{Efficacy of Compound}

QFXYW could be used for treating upper respiratory tract infection, acute bronchitis, chronic bronchitis acute episode and pneumonia, which mainly showing pulmonary retention of begma, asthma, chest and hypochondrium gas pains, expectoration yellow thick, cough with lung heat [19]-[21]. QFXYW had antipyretic and analgesic effects on fever or headache due to upper respiratory tract infections, bronchitis, or pneumonia. By detoxification and disinfection, dephlogisticate effects were had on these diseases for bacterial infections, which fully reflected the dual role of QFXYW in "antipyretic" and "anti-inflammatory” [21].

QFXYW could rapidly eliminate inflammation, restrain the symptoms of cough, sputum and shortness of breath, and effectively shorten the duration [20] [21]. During every treatment phase of respiratory diseases, especially in phase II of sequential therapy, it could be added, the sensitivity could be significantly increased [22].

\section{Efficacy Range and Theoretical Foundation}

In Modern Medicine, respiratory disease was usually treated by bronchodilators, nebulized therapy, anti-inflammatory drugs, asthma andcough medicine [23]-[28]. Cough, the core symptoms of respiratory diseases, corresponded to "Tussis", "Asthma” in Traditional Chinese Medicine [29] [30]. In Traditional Chinese Medicine, coughs were divided into several categories. The most typical one, wind-heat and pulmonary retention of phlegmopyrexia cough, showing cough and shortness of breath, excessive phlegm, chest and hypochondrium engorgement, yellow thick spit, could be healed by QFXYW [22] [31].

Respiratory viral infection is a major cause of "Asthma" and "Tissis" in both children and adults [32]. Among the respiratory viruses, influenzavirus is a particularly important pathogen due to its enormous morbidity and mortality in annual epidemics [33]-[35]. The influenza A (H1N1) emerged in the spring of 2009 and caused the first influenza pandemic in the $21^{\text {st }}$ century [36] [37]. With the emergence of the H1N1 virus, numerous treatment studies were had in patients or animals infected with this virus. At last, QFXYW was approved as the preferred Traditional Chinese Medicine for the prevention and treatment of influenza A (H1N1) in Tianjin [31].

At present, contaminated atmospheric environment by fog and haze had a serious impact on the human health in most Chinese regions. The particulate matter less than or equal to 2.5 microns in diameter (PM 2.5) could enter into the respiratory tract [38], then the tracheal mucosa were stimulated and damaged, the ability of killing viruses and bacteria decreased, which could cause the lung infection [39] [40]. According to the Traditional Chinese Medical theory, the gas ( $\mathrm{PM} \leq 2.5$ ) could stimulate the body to produce fire-heat. The main symptoms included the nasal passages dry, sore, dry cough, spitting sticky yellow, sore throats and chest oppressed. These could be healed by QFXYW [41] [42].

When treating cough, Traditional Chinese Medicine focused highly on dispersion removing obstruction, ra- 
ther than grabbing the evil [43]. During cough, evil was very predominant, so the drug for opening the inhibited lung-energy was preferred, such as Ephedra, Gypsum and Ma Xing Shi Gan Tang. QFXYW from Ma Xing Shi Gan Tang, contained Ephedra and Gypsum. These suggested that QFXYW could be applied to cure respiratory diseases.

\section{Clinical Trials}

\subsection{COPD}

COPD pathological features were chronic inflammation, the airway [44]-[48] vascular remodeling for inflammation injury and repairmen. At present, it ranked No. 4 in the cause of death worldwide [49]. Acute exacerbation of COPD was caused by retention of turbid phlegm in the lung, stagnated heat and adverse rising of pulmonary gas [50] [51]. The syndrome “phlegm-heat stagnating in the lung” was common, QFXYW could treat this acute exacerbation of COPD.

Enshun LIU [52] had investigated the clinical effects of QFXYW on 120 cases. It was found that QFXYW could relieve fever and have a more significant effect on Yellow urine. At the same time, it could effectively relieve the degree of airway obstruction, which was evidenced by the increase of FEV1, (FEV1 measured)/(FEV1 estimated) and FEV1/FVC. In a word, it could alleviate all the symptoms to reduce the risk of disease complications. Dongsheng LI [53] also found that adding QFXYW had better effects than the modern medicine alone. Clinical treating efficiency of cough, expectoration and pulmonary rattle in experimental group were significantly higher than those in control group. Enshun LIU [52] also found that adding QFXYW didn’t improve the sputum color.

\subsection{Children's Viral Pneumonia}

According to Traditional Chinese Medicine theory, children’s viral pneumonia belongs to Cough and Dyspnea, which characteristic werewind-heat closed-lung and phlegm-heat closed lungs [54]. All of 106 cases investigated by Xiaomin ZHAO [55] were wind-heat closed lung, phlegm-heat closed lungs. The duration of rale and fever in adding QFXYW group was significantly shorter than that in the control group. It was also confirmed that the earlier QFXYW was used, the better efficacy was. No adverse effect occurred in adding QFXYW group, while 2 cases with gastrointestinal discomfort turned up in control group [55].

\section{Experiment Studies}

\subsection{Bacteriostasis Experiments in Vitro}

The antibacterial activity in vitro of QFXYW was verificated by Fang Bai [56]. QFXYW had the significant antibacterial and fungicidal effects on Gram-positive bacteris, such as Streptococcus pneumoniae, Streptococcus septic and Staphylococcus aureus [56]. Especially the antibacterial activity to Staphylococcus aureus was very strong, which was 4 - 8 times than that of Lin Shi Yan Ning San and Chuan Jiao Wan [56].

The activity against Gram-negative bacteria of QFXYW was poor. Except Haemophilus influenzae, no significant antibacterial activity to Escherichia coli, Pseudomonas aeruginosa bacteria, Klebsiella pneumoniae, or Proteus was found [56].

QFXYW had no significant effect on the fungi Candida albicans [56].

\subsection{Network of Pharmacological Experiments}

It was found that 19 of 55 chemical compositions of QFXYW might act respectively on the 9 inflammation-related pathway by intervening 11 targets such as HRAS or PDPK 1 [21]. It could significantly improve the infiltration of inflammatory factors in lung tissue, interfere with adhesion plaques, Fc $\varepsilon$ RI, Toll-like receptor, NK cell-mediated cytotoxicity and ERK/MAPK anti-inflammatory pathways by affecting ERK1 geneexpression. The main active ingredients are sulfur-alkyne class represented by Arctic acid (No. 11, and 15, and 18, and 44, and 45), lignanolide class represented by Arctigenin (No. 27, and 48), phenol acid class represented by Sinapic acid (No. 6, and 14, and 16, and 31, and 36, and 38, and 41, and 46) and steroids class compounds represented by Cholic acid. The efficacy representation constituents, Aarctigenin, Cholic acid and Sinapic acid respectively played an anti-inflammatory effect by intervening ERK/MAPK, adhesive patch and Fc $\varepsilon$ RI signaling pathway. 
The gene expression profile of QFXYW related experiments showed that there were totally 55 different expression genes-15 up-regulated genes and 40 down-regulated genes [21]. FAK, ERK1 and Fc $\varepsilon R I-\alpha$ gene expression were significantly reduced, NCR3 gene expression also was reduced. This QFXYW could improve airway inflammation by intervening focal adhesion, Fc Epsilon RI and ERK/MAPK ways. Arctigenin significantly inhibited the increase of FAK and ERK1 gene expression. Cholic acid significantly reduced Fc Epsilon RI $\alpha$ and ERK1 gene expression. Sinapic acid had an efficient inhibitory effect on all of these 3 genes expression. The representative compositions-Arctigenin, Mustard acid and Cholic acid of QFXYW played an anti-inflammatory effect by regulating ERK1, FAK and Fc $\varepsilon$ RI Alpha gene expression and adjusting ERK/MAPK, focal adhesion and Fc $\varepsilon$ RI route. Overall, QFXYW involved in the regulation of focal adhesion, Fc $\varepsilon$ RI, Toll-like receptor, NK cell-mediated cytotoxicity and ERK/MAPK, 5 signal transduction pathways directly related to inflammation, by adjusting the key genes (MAPK3/ERK1) expression.

\subsection{Animal Experiments}

\subsubsection{The Mechanism of Regulating the $\beta 2$ Receptor Pathway to Relieve Asthma}

It was found that citric acid-induced cough was apparently inhibited, the cough frequency was effectively reduced, the cough incubation period was significantly extended in guinea pigs by QFXYW [20] [57] [58]. The contraction of isolated trachea from guinea pigs was significantly inhibited in vitro. The latent period of the histamine-induced asthma was obviously prolonged in guinea pigs.

When the $\beta 2$ receptor was activated, the corresponding effects for reducing and eliminating asthma would be produced, which helped inhibit proliferation and antagonize remodeling of airway smooth muscle [59]-[63]. The ciliary movement could be enhanced in epithelial cells, the absorption of $\mathrm{Na}^{+}$and $\mathrm{Cl}^{-}$was increased, the water exclusion and clear mucus were promoted [64]. The microvascular crack was inhibited, which could avoid leakage in vascular endothelial cells. The synthesis and secretion of surface active material were promoted in alveolar type II cells [65].

When the $\beta 2$ receptor pathway was blocked by blocking agent, $\beta 2$-AR agonist activity of QFXYW disappeared [12]. It proved that the mechanism of inhibiting airway smooth muscle contraction about QFXYW was achieved through the $\beta 2$ AR-mediated g-protein signaling pathways [12].

When the $\beta 2$ receptors-ligand pathway was blocked, the relaxation effect on smooth muscle contraction about QFXYW disappeared. While the pathway was unblocked, the relaxation effect on vascular smooth muscle was obvious. It was deduced that the ephedrine of ephedra played an important role in antasthmatic effect of QFXYW [12].

According to the analysis of the compatibility of QFXYW prescription, Ephedra was the principal drug. By Traditional Chinese Medicine bioactive selecting experiment, the antiasthmatic effect of QFXYW was the strongest in all drugs which contained the same concentration ephedrine [12]. It was speculated that the other ingredients of the prescription could help ephedrine to excite $\beta$-2 receptor. These suggested the good synergy relations between ingredients of this prescription, and the scientific compatibilities of QFXYW.

\subsubsection{The QFXYW Anti-Inflammatory Mechanism by Regulating the Metal Enzyme Expression}

Matrix Metalloproteinases (MMPs) belonged to the endopeptidase family with zinc ions structure activated by calcium ions, MMPs could degradate almost all of extracellular matrix [66]-[69]. They played an important role in disease progression such as inflammation, wound healing and tumor invasion [70]-[73].

Dynamic equilibrium between MMP-9 and TIMP-1 was now considered as a mark of homeostasis between airway tissue destruction and restoration [74]. MMP-9 (gelatinase B) could degradate elastic fiber, gelatin and IV, $\mathrm{V}$ type collagen. It was confirmed that MMP-9 took part in the COPD pathogenesis. COPD mainly showed the destruction of alveolar matrix, alveolar structures, the formation of emphysema airway remodeling, and resulted airflow obstruction [73] [75]. It was reported that the MMP-9 expression in pulmonary parenchyma was significantly associated with smoking and negatively associated with FEV1 [76] [77]. TIMPs were endogenous inhibitor of MMPs, could promote the extracellular matrix (ECM) to deposit, inhibit ECM to degradate, and restrain smooth muscle and epithelial cells to proliferate [78]. In all TIMPs, TIMP-1 was the most active and its specific activity of inhibiting MMP-9 could be induced by a variety of cytokines [79].

In the sputum of COPD patients, the content of MMP-9 and TIMP-1 were significantly higher than those in healthy people, while the value of MMP-9/TIMP-1 was lower than normal [80]. Meanwhile, the ratio (MMP-9/ TIMP-1) was positively associated with the 1th second forced expiratory volume. These indicated that the im- 
balance of MMP-9/TIMP-1 was an important factor for COPD.

Enshun Liu [81] found that the matrix MMP-9 expression in lung tissues of COPD rat increased enormously. It was confirmed that the enzyme took part in the occurrence and development of COPD. In the acute attack stage, COPD was characterized by the imbalance of MMP-9/TIMP-1 resulted from the raising TIMP-1, which caused ECM deposition and airway remodeling [73] [74] [77] [79]. Further research found that with the intervention of QFXYW, MMP-9 and TIMP-1 expression in rats decreased significantly, moreover, the inhibition of the TIMP-1 expression was more efficient [81]. These hinted that the expression inhibition of MMP-9 and TIMP-1 could reduce the degradation of lung matrix, prevent the excessive accrementition of extracellular matrix, and extenuate the remodeling of airway. The above was the main mechanism of QFXYW for regulating MMP to cure COPD.

\section{Prospect}

The clinical trials had confirmed that QFXYW could be used for treating COPD and children's viral pneumonia. It could effectively relieve fever, cough and asthma, improve lung function and duration, and also have no side effect. By the bacteriostasis experiments in vitro and the network pharmacology essays, anti-inflammatory mechanisms were revealed at different levels. Except for the anti-inflammatory and relieving asthma, animal experiments could further elucidate other possible mechanisms. In short, series of studies confirmed that the compatibility of QFXYW was reasonable, which could contribute to relieving fever, cough, asthma and anti-inflammatory. These suggest QFXYW could be used for treating respiratory diseases.

On the basis of mechanism, the cough medicine could be divided into two categories-central and peripheral antitussive [82]. The cough type and effective pathway need to be clarified by further studies. Based on our preexperiment results, QFXYW might have effect on the drug-related chemical receptors, which inhibited the bronchial mucosa stimulation reactivity to cure peripheral antitussive (related results in another paper). The central antitussive effect of QFXYW is still required to be further verified in the center cough model, where laryngeal nerve was stimulated by electricity.

\section{Acknowledgements}

Junying Ding wrote the manuscript, Qingquan Liu revised it critically, all the authors read and approved the final manuscript.

\section{Declaration of Conflicting Interests}

All the authors declare that there are no conflicts of interest.

\section{Funding}

The work was supported by a grant from the National Nature Science Foundation of China (No. 81373813).

\section{References}

[1] Zhou, J., Gao, G., Chu, Q., et al. (2014) Chromatographic Isolation of Nanoparticles from Ma-Xing-Shi-Gan-Tang Decoction and Their Characterization. Journal of Ethnopharmacology, 151, 1116-1123. http://dx.doi.org/10.1016/j.jep.2013.12.029

[2] Hsieh, C.F., Lo, C.W., Liu, C.H., et al. (2012) Mechanism by Which Ma-Xing-Shi-Gan-Tang Inhibits the Entry of Influenza Virus. Journal of Ethnopharmacology, 143, 57-67. http://dx.doi.org/10.1016/j.jep.2012.05.061

[3] Luo, H., Wang, Y., Li, Y., et al. (2009) HPLC Determination of Ephedrine Hydrochloride Content in Qingfei Xiaoyan Pill. World Science and Technology/Modernization of Traditional Chinese Medicine and Materia Medica, 11, 461464.

[4] Wang, Q., Luo, Y., Jin, C., et al. (2008) Effects of Different Drying Methods and Conditions on Anthraquinones and Tannins in Water Extract from Radix et Rhiroma Rhei. Zhong Guo Zhong Yao Za Zhi, 33, 893-896.

[5] Hu, X., Li, W.D., Li, O., et al. (2012) Effect of Gas-Turbine Green Discoloring and Drying Processing Methods on Herbal Quality of Tetraploid Lonicerae Japonicae Flos. Zhong Guo Zhong Yao Za Zhi, 37, 2554-2557.

[6] Li, L.M. and Zhu, Y. (2012) Effects of Complement Inhibiting Component of Ephedra sinica on Immunological Inflammation Following Acute Spinal Cord Injury in Rats. Zhong Guo Zhong Xi Yi Jie He Za Zhi, 32, 1385-1389. 
[7] Song, M.K., Um, J.Y., Jang, H.J., et al. (2012) Beneficial Effect of Dietary Ephedra sinica on Obesity and Glucose Intolerance in High-Fat Diet-Fed Mice. Experimental and Therapeutic Medicine, 3, 707-712.

[8] Ikarashi, N., Ogiue, N., Toyoda, E., et al. (2013) Elucidating the Mechanism by Which Gypsum Fibrosum, A Traditional Chinese Medicine, Maintains Cutaneous Water Content. Biological Pharmaceutical Bulletin, 36, 1615-1621. http://dx.doi.org/10.1248/bpb.b13-00494

[9] Ikarashi, N., Ogiue, N., Toyoda, E., et al. (2012) Gypsum Fibrosum and Its Major Component CaSO 4 Increase Cutaneous Aquaporin-3 Expression Levels. Journal of Ethnopharmacology, 139, 409-413. http://dx.doi.org/10.1016/j.jep.2011.11.025

[10] Tanaka, R., Nitta, A. and Nagatsu, A. (2014) Application of a Quantitative (1) H-NMR Method for the Determination of Amygdalin in Persicae Semen, Armeniacae Semen, and Mume Fructus. Journal of Natural Medicines, 68, 225-230. http://dx.doi.org/10.1007/s11418-013-0783-y

[11] Jia, J.J., Zeng, X.S., Li, Y., Ma, S. and Bai, J. (2013) Ephedrine Induced Thioredoxin-1 Expression through $\beta$-Adrenergic Receptor/Cyclic AMP/Protein Kinase A/Dopamine- and Cyclic AMP-Regulated Phosphoprotein Signaling Pathway. Cellular Signalling, 25, 1194-1201. http://dx.doi.org/10.1016/j.cellsig.2013.02.007

[12] Cheng, B.F., Hou, Y.Y., Wang, L.Q., Dong, L.Y., Peng, J.M. and Bai, G. (2012) Dual-Bioactivity-Based Liquid Chromatography-Coupled Quadrupole Time-of-Flightmassspec-Trometry for NF- $\mathrm{BB}$ Inhibitors and $\beta_{2} \mathrm{AR}$ Agonists Identification in Chinese Medicinal Preparation Qingfei Xiaoyan Wan. Analytical and Bioanalytical Chemistry, 404, 2445-2452. http://dx.doi.org/10.1007/s00216-012-6332-9

[13] Xu, Z., Ju, J., Wang, K., Gua, C.C. and Feng, Y. (2014) Evaluation of Hypoglycemic Activity of Total Lignans from Fructus arctii in the Spontaneously Diabetic Goto-Kakizaki Rats. Journal of Ethnopharmacology, 151, 548-555. http://dx.doi.org/10.1016/j.jep.2013.11.021

[14] Lee, H.D. and Chiu, H.H. (2012) A Case of Unilateral Pleural Effusion Secondary to Congestive Heart Failure Successfully Treated with Traditional Chinese Herbal Formulas. Journal of Alternative and Complementary Medicine, 18, 509-512. http://dx.doi.org/10.1089/acm.2011.0292

[15] He, K.B., Wang, Y.Z., Feng, A.L., Duan, F.P., Li, C.X. and Sun, X.Y. (2013) Preparation of Kushen-Dilong Nanoemulsion Gel and Transdermal Characterization in Vitro. Zhong Guo Zhong Yao Za Zhi, 38, 2623-2627.

[16] Ma, H.Y., Zhou, J., Jiang, J.J., Duan, J., Xu, H.Q., Tang, Y.P., Lv, G.H., Zhang, J.F., Zhan, Z. and Ding, A.W. (2012) The Novel Antidote Bezoar Bovis Prevents the Cardiotoxicity of Toad (Bufo bufo gargarizans Canto) Venom in Mice. Experimental and Toxicologic Pathology, 64, 417-423. http://dx.doi.org/10.1016/j.etp.2010.10.007

[17] Shimizu, Y., Suzuki, T., Oda, K. and Morishita, S. (1999) Pharmacological Studies of Reiousan, a Drug Containing Bezoar and Ginseng_Effects on the Blood Rheology. Yakugaku Zasshi, 119, 731-741.

[18] Liu, Y., Zhang, G.J. and Sun, S.Q. (2010) Study on Rapid Identification of Cornu Saigae Tataricae and Cornu Antelopis Block by Fourier Transform Infrared Spectroscopy. Guang Pu Xue Yu Guang Pu Fen Xi, 30, 42-44.

[19] Zhang, X., Pang, H.L. and Yu, X.H. (2013) Evaluation on the Clinical Application of Qingfei Anti-Inflammatory Pills. Evaluation and Analysis of Drug-Use in Hospitals of China, 13, 780-781.

[20] Zhao, Z.Y., Miao, Y.B., Pan, P.W., Cheng, B.F., Bai, G. and Wu, H. (2013) Qingfei Xiaoyan Wan Alleviates Asthma through Multi-Target Network Regulation. BMC Complementary and Alternative Medicine, 13, 206. http://dx.doi.org/10.1186/1472-6882-13-206

[21] Cheng, B.F., Hou, Y.Y., Jiang, M., Zhao, Z.Y., Dong, L.Y. and Bai, G. (2013) Anti-Inflammatory Mechanism of Qingfei Xiaoyan Wan Studied with Network Pharmacology. Үaо Хие Хие Вao, 48, 686-693.

[22] Ren, D. (2011) Antitussive Qing Fei Xiao Yan Wan Is Safer. Kai JuanYou Yi (Qiu Yi Wen Yao), $12,26$.

[23] Bollu, V., Ernst, F.R., Karafilidis, J., Rajagopalan, K., Robinson, S.B. and Braman, S.S. (2013) Hospital Readmissions Following Initiation of Nebulized Arformoterol Tartrate or Nebulized Short-Acting Beta-Agonists among Inpatients Treated for COPD. International Journal of Chronic Obstructive Pulmonary Disease, 8, 631-639. http://dx.doi.org/10.2147/COPD.S52557

[24] Spina, D. (2014) Current and Novel Bronchodilators in Respiratory Disease. Current Opinion in Pulmonary Medicine, 20, 73-86. http://dx.doi.org/10.1097/MCP.0000000000000012

[25] Seth, H.D., Sultan, S. and Gotfried, M.H. (2013) Role of Indacaterol, a Once-Daily Bronchodilator, in Chronic Obstructive Pulmonary Disease. Journal of Thoracic Disease, 5, 806-814.

[26] Hoza, J., Salzman, R., Starek, I., Schalek, P. and Kellnerova, R. (2013) Efficacy and Safety of Erdosteine in the Treatment of Chronic Rhinosinusitis with Nasal Polyposis-A Pilot Study. Rhinology, 51, 323-327.

[27] Theron, A.J., Steel, H.C., Tintinger, G.R., Feldman, C. and Anderson, R. (2013) Can the Anti-Inflammatory Activities of $\beta 2$-Agonists Be Harnessed in the Clinical Setting. Drug Design, Development and Therapy, 7, 1387-1398. http://dx.doi.org/10.2147/DDDT.S50995 
[28] Beigel, J. and Bray, M. (2008) Current and Future Antiviral Therapy of Severe Seasonal and Avian Influenza. Antiviral Research, 78, 91-102. http://dx.doi.org/10.1016/j.antiviral.2008.01.003

[29] Chen, D., Zhang, F.B., Tang, S.H., Chen, Y., Lu, P., Wen, S.X., et al. (2013) A Network-Based Systematic Study for the Mechanism of the Treatment of Zhengs Related to Cough Variant Asthma. Evidence-Based Complementary and Alternative Medicine, 2013, Article ID: 595924.

[30] Shao, S.J., Quan, C.F., Shao, S.X., Zhou, M., Jing, X.J., Zhao, Y.X., Ren, Z.X., Wang, P.Y., Gao, X.Y., Yang, J., Ren, Z. and Kong, L. (2013) Asthma at Acute Attack Stage Treated with “Shao's Five Needling Therapy”: A Multi-Central Randomized Controlled Study. Zhong Guo Zhen Jiu, 33, 774-778.

[31] Ren, D. (2012) How to Deal with “Lung Fire” in Spring. Kai Juan You Yi, 3, 34.

[32] Obuchi, M., Adachi, Y., Takizawa, T. and Sata, T. (2013) Influenza $\mathrm{A}\left(\mathrm{H}_{1} \mathrm{~N}_{1}\right) \mathrm{pdm09}$ Virus and Asthma. Frontiers in Microbiology, 4, 307. http://dx.doi.org/10.3389/fmicb.2013.00307

[33] Tsukagoshi, H., Ishioka, T., Noda, M., Kozawa, K. and Kimura, H. (2013) Molecular Epidemiology of Respiratory Viruses in Virus-Induced Asthma. Frontiers in Microbiology, 4, 278. http://dx.doi.org/10.3389/fmicb.2013.00278

[34] Kimura, H., Yoshizumi, M., Ishii, H., Oishi, K. and Ryo, A. (2013) Cytokine Production and Signaling Pathways in Respiratory Virus Infection. Frontiers in Microbiology, 4, 276. http://dx.doi.org/10.3389/fmicb.2013.00276

[35] Khattab, A., Shaheen, M., Kamel, T., El Faramay, A., Abd El Rahman, S., Nabil, D. and Gouda, M. (2013) Burden of Pediatric Influenza A Virus Infection Post Swine-Flu $\mathrm{H}_{1} \mathrm{~N}_{1}$ Pandemic in Egypt. Asian Pacific Journal of Tropical Medicine, 6, 693-698. http://dx.doi.org/10.1016/S1995-7645(13)60120-0

[36] Green, M.E., Wong, S.T., Lavoie, J.G., Kwong, J., MacWilliam, L., Peterson, S., Liu, G.Y. and Katz, A. (2013) Admission to Hospital for Pneumonia and Influenza Attributable to 2009 Pandemic A/ $\mathrm{H}_{1} \mathrm{~N}_{1}$ Influenza in First Nations Communities in Three Provinces of Canada. BMC Public Health, 13, 1029. http://dx.doi.org/10.1186/1471-2458-13-1029

[37] Pohl, J.B., Mayet, A., Beubourg, G., Duron, S., Michel, R., Deparis, X., et al. (2014) The 2009 A $\left(\mathrm{H}_{1} \mathrm{~N}_{1}\right)$ Influenza Pandemic in the French Armed Forces: Epidemiological Surveillance and Operational Management. Military Medicine, 179, 183-189. http://dx.doi.org/10.7205/MILMED-D-13-00261

[38] Wang, J., Shu, J.Z. and Chen, X.Y. (2013) The Effect of PM2.5 Carrier Components on Respiratory Health. Zhong Hиа Jie Не Не Нu Xi Za Zhi, 36, 970-972.

[39] Fu, M.N., Zheng, Y.F., Xu, X.S. and Niu, L. (2011) Advances of Study on Monitoring and Evaluation of PM2.5. Meteorology and Disaster Reduction Research, 34, 1-6.

[40] Li, W., Mao, B., Wang, G., Wang, L., Chang, J., Zhang, Y., Wan, M.H. and Guo, J. (2008) A Study of the Mechanism of Qingre Huatan Therapy in Treatment of Acute Exacerbation of Chronic Obstructive Pulmonary Disease by Improving Airway Inflammation and Mucus Hypersecretion. Zhong Xi Yi Jie He Xue Bao, 6, 799-805. http://dx.doi.org/10.3736/jcim20080806

[41] Li, J.S., Li, S.Y., Xie, Y., Yu, X.Q., Wang, M.H., Sun, Z.K., et al. (2013) The Effective Evaluation on Symptoms and Quality of Life of Chronic Obstructive Pulmonary Disease Patients Treated by Comprehensive Therapy Based on Traditional Chinese Medicine Patterns. Complementary Therapies in Medicine, 21, 595-602. http://dx.doi.org/10.1016/j.ctim.2013.09.006

[42] Ren, D. (2012) Qing Fei Xiao Yan Wan Had Good Effect on Clearing away the Lung-Heat. Kai Juan You Yi, 9, 30.

[43] Zhang, Y., Xiao, W., Jiang, Y., Wang, H., Xu, X., Ma, D., Chen, H. and Wang, X. (2012) Levels of Components of the Urokinase-Type Plasminogen Activator System Are Related to Chronic Obstructive Pulmonary Disease Parenchymal Destruction and Airway Remodelling. Journal of International Medical Research, 40, 976-985. http://dx.doi.org/10.1177/147323001204000316

[44] Vlahos, R. and Bozinovski, S. (2014) Recent Advances in Pre-Clinical Mouse Models of COPD. Clinical Science, 126, 253-265. http://dx.doi.org/10.1042/CS20130182

[45] Sohal, S.S., Ward, C., Danial, W., Wood-Baker, R. and Walters, E.H. (2013) Recent Advances in Understanding Inflammation and Remodeling in the Airways in Chronic Obstructive Pulmonary Disease. Expert Review of Respiratory Medicine, 7, 275-288. http://dx.doi.org/10.1586/ers.13.26

[46] Rab, A., Rowe, S.M., Raju, S.V., Bebok, Z., Matalon, S. and Collawn, J.F. (2013) Cigarette Smoke and CFTR: Implications in the Pathogenesis of COPD. American Journal of Physiology-Lung Cellular and Molecular Physiology, 305, L530-L541. http://dx.doi.org/10.1152/ajplung.00039.2013

[47] Huang, C.P., Xie, M.Y., He, X.H. and Gao, H. (2013) Activity of Sputum p38 MAPK Is Correlated with Airway Inflammation and Reduced FEV1 in COPD Patients. Medical Science Monitor, 19, 1229-1235. http://dx.doi.org/10.12659/MSM.889880

[48] Shen, L.L., Liu, Y.N., Shen, H.J., Wen, C., Jia, Y.L., Dong, X.W., Jin, F., Chen, X.P., Sun, Y. and Xie, Q.M. (2014) Inhalation of Glycopyrronium Inhibits Cigarette Smoke-Induced Acute Lung Inflammation in a Murine Model of 
COPD. International Immunopharmacology, 18, 358-364. http://dx.doi.org/10.1016/j.intimp.2013.12.021

[49] Løkke, A., Hilberg, O., Tønnesen, P., Ibsen, R., Kjellberg, J. and Jennum, P. (2014) Direct and Indirect Economic and Health Consequences of COPD in Denmark: A National Register-Based Study: 1998-2010. BMJ Open, 4, Article ID: e004069. http://dx.doi.org/10.1136/bmjopen-2013-004069

[50] Camp, P., Reid, W.D., Yamabayashi, C., Brooks, D., Goodridge, D., Chung, F., Marciniuk, D.D., Neufeld, A. and Hoens, A. (2013) Safe and Effective Prescription of Exercise in Acute Exacerbations of Chronic Obstructive Pulmonary Disease: Rationale and Methods for an Integrated Knowledge Translation Study. Canadian Respiratory Journal, 20, 281-284.

[51] Reissmann, H.K., Ranieri, V.M., Goldberg, P. and Gottfried, S.B. (2000) Continuous Positive Airway Pressure Facilitates Spontaneous Breathing in Weaning Chronic Obstructive Pulmonary Disease Patients by Improving Breathing Pattern and Gas Exchange. Intensive Care Medicine, 26, 1764-1772. http://dx.doi.org/10.1007/s001340000725

[52] Liu, E., Sun, Z.T., Li, Y.Y., et al. (2010) AECOPD (Phlegm Obstruct the Lung) Clinical Observation on 120 Cases of Qingfei Xiaoyan Wan. Chinese Medicine Modern Distance Education of China, 8, 149-150.

[53] Li, D.S. and Gao, S. (2003) Clinical Observation on Acute Exacerbation of Chronic Bronchitis Treated by Integrative Medicine. Tianjin Journal of Traditional Chinese Medicine, 20, 41.

[54] Yang, Y., Wang, S.C. and Li, R.L. (2010) Effect of Qingkailing Injection on Children with Respiratory Syncytial Virus Pneumonia of Phlegm-Heat Obstructing Fei Syndrome Pattern at Different Time-Points. Zhong Guo Zhong Xi Yi Jie He Za Zhi, 30, 908-911.

[55] Zhao, X.M. (2007) Clinical Observation on Children with Viral Pneumonia Treated by Qingfei Xiaoyan Wan Combined with Western Medicine. Chinese Traditional and Herbal Drugs, 37, 1384-1385.

[56] Bai, F., Rong, Z.D., Bai, G., et al. (2012) Researches on Antibacterial Activity of Qingfei Xiaoyan Wan in Vitro. Drug Evaluation Research, 35, 106-108.

[57] Hou, Y.Y., Li, R.J., Shi, Q., Cheng, B., Wang, L. and Bai, R. (2009) Investigation of the Anti-asthmatic Mechanism of Qing Fei Xiao Yan Wan. Acta Scientiarum Naturalium Universitatis Nankaiensis, 42, 103-107.

[58] Hou, Y.Y., Li, R.J., Cheng, B.F., et al. (2010) Function Study on Clearing Asthma of Qingfei Xiaoyan Wan in Guinea Pigs. Drug Evaluation Research, 33, 103-105.

[59] Qian, L., Wu, H.M., Chen, S.H., Zhang, D., Ali, S.F., Peterson, L., Wilson, B., Lu, R.B., Hong, J.S. and Flood, P.M. (2011) $\beta$-Adrenergic Receptor Activation Prevents Rodent Dopaminergic Neurotoxicity by Inhibiting Microglia via a Novel Signaling Pathway. Journal of Immunology, 186, 4443-4454. http://dx.doi.org/10.4049/jimmunol.1002449

[60] Ueki, T., Akaishi, T., Okumura, H. and Abe, K. (2012) Extract from Nandina domestica Inhibits LipopolysaccharideInduced Cyclooxygenase-2 Expression in Human Pulmonary Epithelial A549 Cells. Biological and Pharmaceutical Bulletin, 35, 1041-1047. http://dx.doi.org/10.1248/bpb.b110709

[61] Holden, N.S., George, T., Rider, C.F., Chandrasekhar, A., Shah, S., Kaur, M., et al. (2014) Induction of Regulator of G-Protein Signaling 2 Expression by Long-Acting $\beta 2$-Adrenoceptor Agonists and Glucocorticoids in Human Airway Epithelial Cells. Journal of Pharmacology and Experimental Therapeutics, 348, 12-24. http://dx.doi.org/10.1124/jpet.113.204586

[62] Liu, X.R., Tan, W., Liu, Y., Lin, G.P. and Xie, C.M. (2013) The Role of the $\beta 2$ Adrenergic Receptor on Endothelial Progenitor Cells Dysfunction of Proliferation and Migration in Chronic Obstructive Pulmonary Disease Patients. Expert Opinion on Therapeutic Targets, 17, 485-500. http://dx.doi.org/10.1517/14728222.2013.773975

[63] Baloğlu, E., Ke, A., Abu-Taha, I.H., Bärtsch, P. and Mairbäurl, H. (2009) In Vitro Hypoxia Impairs $\beta 2$-Adrenergic Receptor Signaling in Primary Rat Alveolar Epithelial Cells. American Journal of Physiology-Lung Cellular and Molecular Physiology, 296, L500-L509. http://dx.doi.org/10.1152/ajplung.90390.2008

[64] Fidzinski, P., Salvador-Silva, M., Choritz, L., Geibel, J. and Coca-Prados, M. (2004) Inhibition of NHE-1 Na ${ }^{+} / \mathrm{H}^{+} \mathrm{Ex}^{-}$ changer by Natriuretic Peptides in Ocular Nonpigmented Ciliary Epithelium. American Journal of Physiology-Cell Physiology, 287, C655-C663. http://dx.doi.org/10.1152/ajpcell.00552.2003

[65] Kankavi, O., Ata, A. and Gungor, O. (2007) Surfactant Proteins A and D in the Genital Tract of Mares. Animal Reproduction Science, 98, 259-270. http://dx.doi.org/10.1016/j.anireprosci.2006.03.009

[66] Chen, Q., Jin, M., Yang, F., Zhu, J.H., Xiao, Q.Z. and Zhang, L. (2013) Matrix Metalloproteinases: Inflammatory Regulators of Cell Behaviors in Vascular Formation and Remodeling. Mediators of Inflammation, 2013, Article ID: 928315. http://dx.doi.org/10.1155/2013/928315

[67] Lee, I.T. and Yang, C.M. (2013) Inflammatory Signalings Involved in Airway and Pulmonary Diseases. Mediators of Inflammation, 2013, Article ID: 791231. http://dx.doi.org/10.1155/2013/791231

[68] Kucukguven, A. and Khalil, R.A. (2013) Matrix Metalloproteinases as Potential Targets in the Venous Dilation Associated with Varicose Veins. Current Drug Targets, 14, 287-324. 
[69] Knapinska, A. and Fields, G.B. (2012) Chemical Biology for Understanding Matrix Metalloproteinase Function. Chembiochem, 13, 2002-2020. http://dx.doi.org/10.1002/cbic.201200298

[70] Halade, G.V., Jin, Y.F. and Lindsey, M.L. (2013) Matrix Metalloproteinase (MMP)-9: A Proximal Biomarker for Cardiac Remodeling and a Distal Biomarker for Inflammation. Pharmacology \& Therapeutics, 139, 32-40. http://dx.doi.org/10.1016/j.pharmthera.2013.03.009

[71] Martins, V.L., Caley, M. and O’Toole, E.A. (2013) Matrix Metalloproteinases and Epidermal Wound Repair. Cell and Tissue Research, 351, 255-268. http://dx.doi.org/10.1007/s00441-012-1410-z

[72] Wieczorek, E., Reszka, E., Gromadzinska, J. and Wasowicz, W. (2012) Genetic Polymorphism of Matrix Metalloproteinases in Breast Cancer. Neoplasma, 59, 237-247. http://dx.doi.org/10.4149/neo_2012_031

[73] Lagente, V., Manoury, B., Nenan, S., Le Quément, C., Martin-Chouly, C. and Boichot, E. (2005) Role of Matrix Metalloproteinases in the Development of Airway Inflammation and Remodeling. Brazilian Journal of Medical and Biological Research, 38, 1521-1530. http://dx.doi.org/10.1590/S0100-879X2005001000009

[74] Yao, H., Hwang, J.W., Sundar, I.K., Friedman, A.E., McBurney, M.W., Guarente, L., et al. (2013) SIRT1 Redresses the Imbalance of Tissue Inhibitor of Matrix Metalloproteinase-1 and Matrix Metalloproteinase-9 in the Development of Mouse Emphysema and Human COPD. American Journal of Physiology-Lung Cellular and Molecular Physiology, 305, L615-L624. http://dx.doi.org/10.1152/ajplung.00249.2012

[75] Muroski, M.E., Roycik, M.D., Newcomer, R.G., Van den Steen, P.E., Opdenakker, G., Monroe, H.R. and Sahab, Z.J. (2008) Matrix Metalloproteinase-9/Gelatinase B Is a Putative Therapeutic Target of Chronic Obstructive Pulmonary Disease and Multiple Sclerosis. Current Pharmaceutical Biotechnology, 9, 34-46. http://dx.doi.org/10.2174/138920108783497631

[76] van Diemen, C.C., Postma, D.S., Siedlinski, M., Blokstra, A., Smit, H.A. and Boezen, H.M. (2011) Genetic Variation in TIMP1 but Not MMPs Predict Excess FEV1 Decline in Two General Population-Based Cohorts. Respiratory Research, 12, 57. http://dx.doi.org/10.1186/1465-9921-12-57

[77] Riggins, K.S., Mernaugh, G., Su, Y., Quaranta, V., Koshikawa, N., Seiki, M., Pozzi, A. and Zent, R. (2010) MT1MMP-Mediated Basement Membrane Remodeling Modulates renal Development. Experimental Cell Research, 316, 2993-3005. http://dx.doi.org/10.1016/j.yexcr.2010.08.003

[78] Polimeni, M., Valente, E., Ulliers, D., Giribaldi, G., Prato, M., Opdenakker, G., et al. (2013) Natural Haemozoin Induces Expression and Release of Human Monocyte Tissue Inhibitor of Metalloproteinase-1. PLoS ONE, 8, Article ID: e71468. http://dx.doi.org/10.1371/journal.pone.0071468

[79] Xin, X.F., Zhao, M., Li, Z.L., Song, Y. and Shi, Y. (2007) Metalloproteinase-9/Tissue Inhibitor of Metalloproteinase-1 in Induced Sputum in Patients with Asthma and Chronic Obstructive Pulmonary Disease and Their Relationship to Airway Inflammation and Airflow Limitation. Zhong Hua Jie He He Hu Xi Za Zhi, 30, 192-196.

[80] Liu, E., Liu, W., Sun, Z.T., Su, J.S. and Guan, P. (2013) Effect of Qingfei Xiaoyan Pills on the Expression of MMP-9 and TIMP-1 in the Lung Tissue of COPD Rats. World Chinese Medicine, 8, 649-651.

[81] Liu, W., Sun, Z.T., Liu, E., et al. (2010) Research on Qingfei Xiaoyan Wan Mechanism of COPD Acute Exacerbation in Rats. Chinese Medicine Modern Distance Education of China, 8, 156-157.

[82] Bolser, D.C. (1996) Mechanisms of Action of Central and Peripheral Antitussive Drugs. Pulmonary Pharmacology, 9, 357-364. http://dx.doi.org/10.1006/pulp.1996.0047 
Scientific Research Publishing (SCIRP) is one of the largest Open Access journal publishers. It is currently publishing more than 200 open access, online, peer-reviewed journals covering a wide range of academic disciplines. SCIRP serves the worldwide academic communities and contributes to the progress and application of science with its publication.

Other selected journals from SCIRP are listed as below. Submit your manuscript to us via either submit@scirp.org or Online Submission Portal.
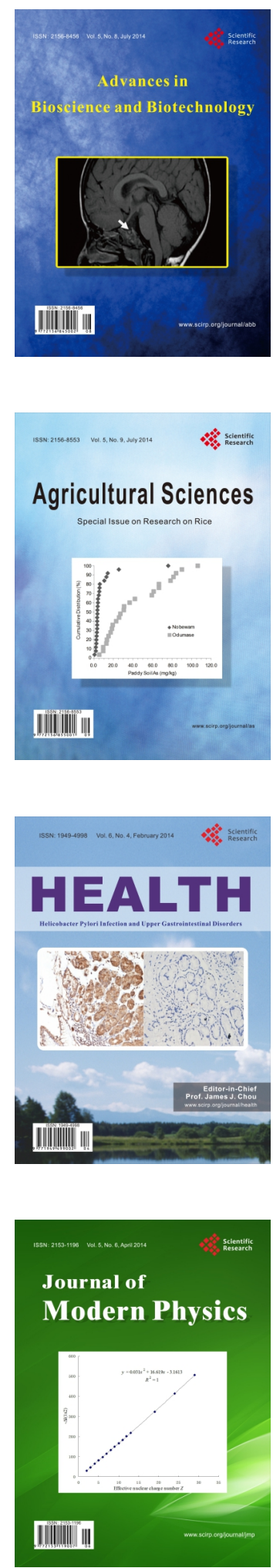
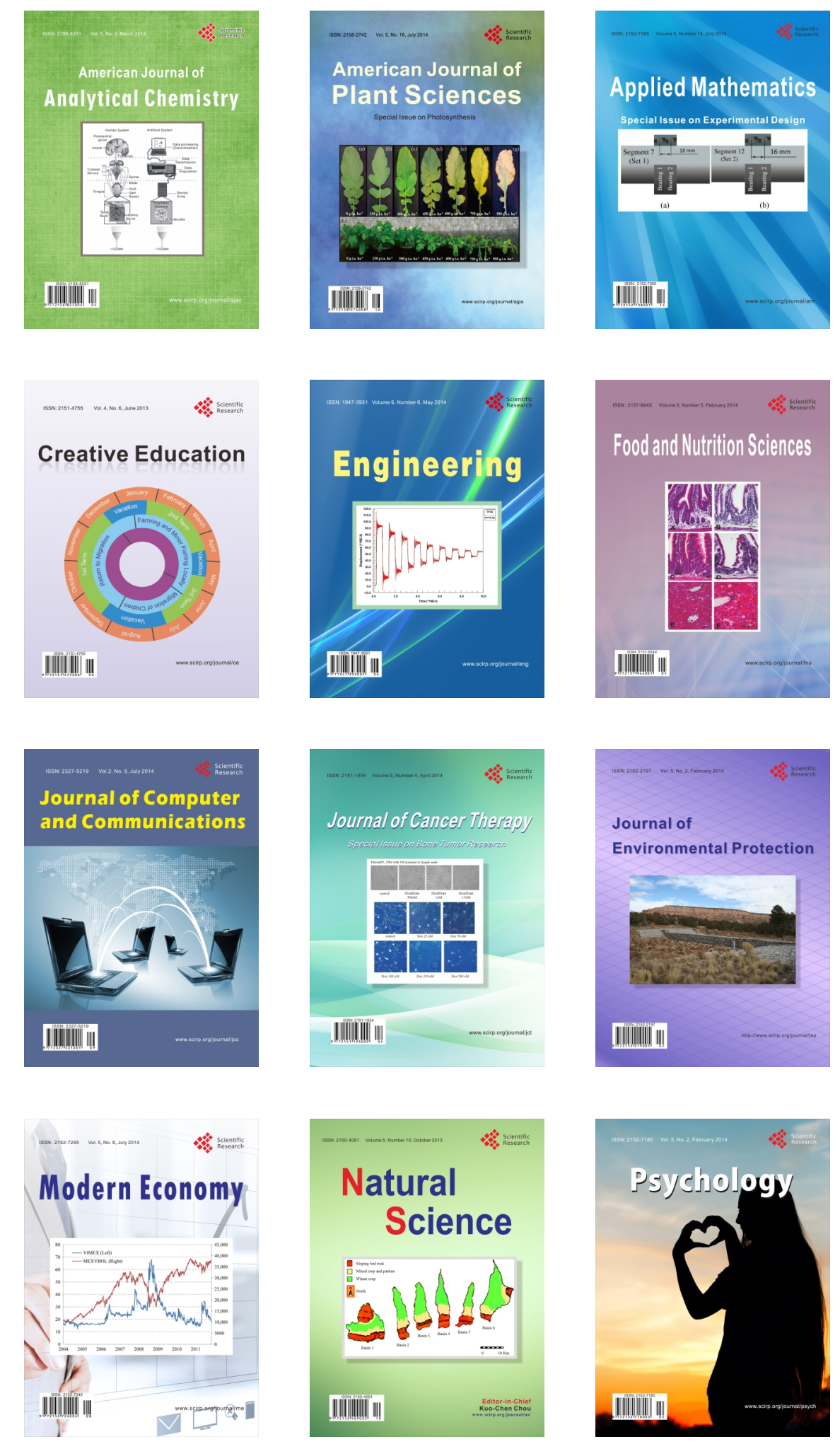